\title{
Spatial structure of an intertidal sandflat microphytobenthic community as related to different spatial scales
}

\author{
Maria A. Saburova ${ }^{1, *}$, Igor G. Polikarpov ${ }^{1}$, Igor V. Burkovsky ${ }^{2}$ \\ ${ }^{1}$ Institute of Biology of the Southern Seas, Prospekt Nakhimova, 2, 335011 Sevastopol, Crimea, Ukraine \\ ${ }^{2}$ Department of Hydrobiology, Biological Faculty, Moscow State University, Vorobjevy Gory, 119899 Moscow, Russia
}

\begin{abstract}
Investigations were carried out on an intertidal sandflat (Kandalaksha Gulf, the White Sea, Russia) during the summers of 1988 to 1992. Analysis of samples collected from areas of different sizes furnished information on the distribution of microphytobenthic organisms (diatoms and dinoflagellates) over 3 spatial scales: microscale $\left(10\right.$ to $\left.1000 \mathrm{~cm}^{2}\right)$, mesoscale $\left(1000 \mathrm{~cm}^{2}\right.$ to $\left.100 \mathrm{~m}^{2}\right)$ and macroscale $\left(100\right.$ to $\left.10000 \mathrm{~m}^{2}\right\}$. Analyses of the data disclosed the aggregated character of distribution on all spatial scales for the majority of dominating microalgal species and the existence of 2 orders of aggregation. The spatial structures formed by aggregates of the first and second orders are noticeably different from each other in the degree of aggregation (Cassie Index of 0.5 and $>2$ on average, respectively), overlapping of species distributions (Pianka Index of 0.5 and 0.3 on average) and degree of similarity of species structure (Pianka lndex of 0.9 and 0.5 on average). This indicates the existence of several structural associations on the studied intertidal sandflat which differed from each other in species composition and the character of spatial distribution of organisms. The studied community had a highly complicated spatial structure. The presence of several orders of aggregation probably results from several main biotic (interspecies interaction) and abiotic (granulometric composition of sediments and emersion period during low tide) factors. The degree of influence of these factors on the character of spatial distribution of microalgae is related to the selected spatial scale.
\end{abstract}

KEY WORDS: Microalgae - Spatial distribution - Spatial scales - Aggregation - Intertidal sediments

\section{INTRODUCTION}

Investigation of spatial distribution of organisms contributes to a better understanding of many problems associated with community structure and function. Such information is often the best, if not only, path for retracing different interspecific interactions, which to a considerable extent determine community structure.

The spatial structure of microphytobenthic communities on soft sediments has been studied by various investigators for years, providing interpretations of the complicated spatial structure and aggregated character of microalgal distribution. The existence of patches,

\footnotetext{
•E-mail: root@inbum.sebastopol.ua
}

caused by mass development of diatoms, dinoflagellates, and green and euglenoid algae, has been reported by many researchers (Faure-Fremiet 1951, Hirano 1967, Fenchel 1969, Joseph \& Joseph 1977, Blanchard 1990, Paterson \& Underwood 1990).

Plante et al. (1986) established 3 scales of heterogeneity in the distribution of chlorophyll $a$ in sediments of the sandy sublittoral zone of the northern Mediterranean: micro- (3 to $10 \mathrm{~cm})$, meso- (ca $10 \mathrm{~m})$ and macroscale (ca $10 \mathrm{~km}$ ); chlorophyll a distribution in sediments was classified for 3 types of topographic features of the sediment surface: sandy ripple and 2 types of sandy waves. Chlorophyll a aggregations are comparable in size with the relief features.

Delgado (1989), in contrast, noted the absence of significant differences in the extent of heterogenous distribution of chlorophyll $a$ with $10 \mathrm{~cm}$ and $10 \mathrm{~m}$ scales. 
Skjoldal (1982) also reported minor variation (CV about $10 \%$ ) in distribution of chlorophyll $a$ in an area of $4 \mathrm{~m}^{2}$ Both authors emphasized the importance of wave activity in the formation of an abundance of microphytobenthos in various areas.

Pinckney \& Sandulli (1990) investigated the microscale distribution of microphytobenthos and meiobenthos, concentrating on the leading role played by such biotic factors as predation or competition in the formation of non-occasional organism distribution. They gave no direct evidence of the existence of such influence.

Other factors that influence spatial distribution of microalgae are light intensity on the sediment surface, hydrodynamics, and the granulometric composition of sediments (Fenchel 1969, Colijn \& Dijkema 1981, Delgado 1989).

Data obtained by all these investigators establish the presence of an intricate complex of abiotic and biotic factors that affect the spatial distribution of microphytobenthic organisms on different spatial scales. However, the literature on important characteristics of distribution such as level of aggregation or patch size is often contradictory. Not always are these and other parameters compared on different spatial scales. It is noteworthy that many references to the spatial distribution of microalgae are based on measurements of photosynthetic pigment concentration in sediments. However, the published information is not always sufficient to allow an assessment of large taxonomic groups of microalgae, to say nothing of different species.

Therefore we attempted to study the spatial structure of a microphytobenthic community on different spatial scales and the factors which determine this structure.

\section{MATERIALS AND METHODS}

Study sites. The study was carried out on the intertidal sandflat of the small Chernaya Bay (Kandalaksha Gulf, the White Sea, Russia) during the summers of 1988 to 1992 (Fig. 1, Table 1). The bay is well protected against strong breakers, but is exposed from the SE to wind activities that affect the complex of tidal currents which drive the formation of the relief and sediments of the sandflat. The studied sediment is fine-grained sand (modal size of particles is 0.10 to $0.25 \mathrm{~mm}$ ), slightly silty (2 to $10 \%$ aleuropelite fraction) and oligosaprobic (organic carbon content up to $1 \%$ of sediment dry weight). The upper boundary of the reduced zone $(E h<0 \mathrm{mV})$ is at a depth of 1 to $6 \mathrm{~cm}$; the boundary of the photic zone ( $>1 \%$ from total solar radiation) extends to between 2.5 and $3.0 \mathrm{~mm}$. The sediment surface consists of different topographic features occurring at the mesoscale (irregular mounds 8 to $10 \mathrm{~m}$ long, 3 to $4 \mathrm{~m}$ wide and up to 0.3 to $0.5 \mathrm{~m}$ high, and the depressions between them) and at the macroscale (regular increase of absolute altitude above low-water datum from the lower to the upper intertidal zone) (Fig. 1). The air exposure of sediments during the exposure period varied from between 0 and $4 \mathrm{~h} \mathrm{~d}^{-1}$ on the lower tidal zone to between 16 and $20 \mathrm{~h} \mathrm{~d}^{-1}$ on the upper one (Burkovsky 1992).

Sample collection. Sampling was conducted during low tides with a plastic tube $\left(1 \mathrm{~cm}^{2}\right.$ section, to a depth of $1 \mathrm{~cm}$ ) or by cutting out sediment blocks of the required size with a sharp knife. Data on the distribution of microphytobenthos were collected from areas of $10 \mathrm{~cm}^{2}$ up to $10000 \mathrm{~m}^{2}$ in size ( 8 orders of magnitude) permitting an evaluation of the distribution of species on different spatial scales (Table 1). All studied areas were arbitrarily divided into micro- $\left(10 \mathrm{~cm}^{2}\right.$ to $\left.2.3 \mathrm{~m}^{2}\right)$, meso-

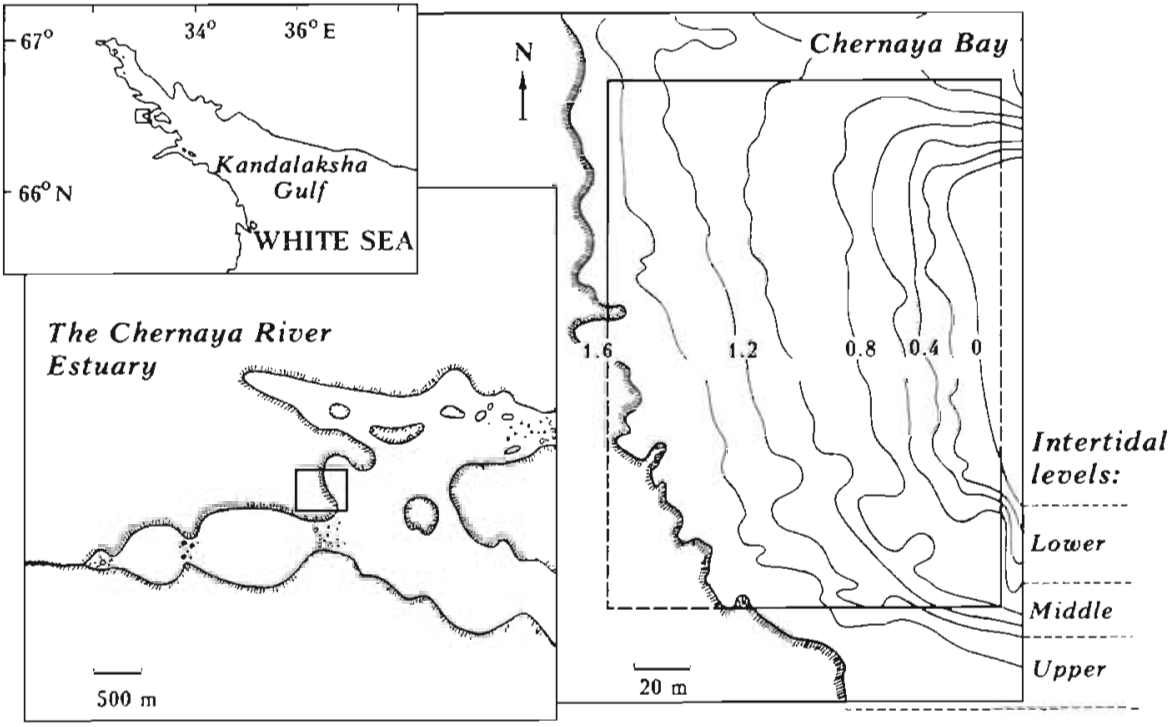

Fig. 1. Area of investigation. Values in the right-hand part of the figure are absolute altitude $(\mathrm{m})$ relative to low water datum 
Table 1. Sample number, sample sizes and sampling methods used in this investigation

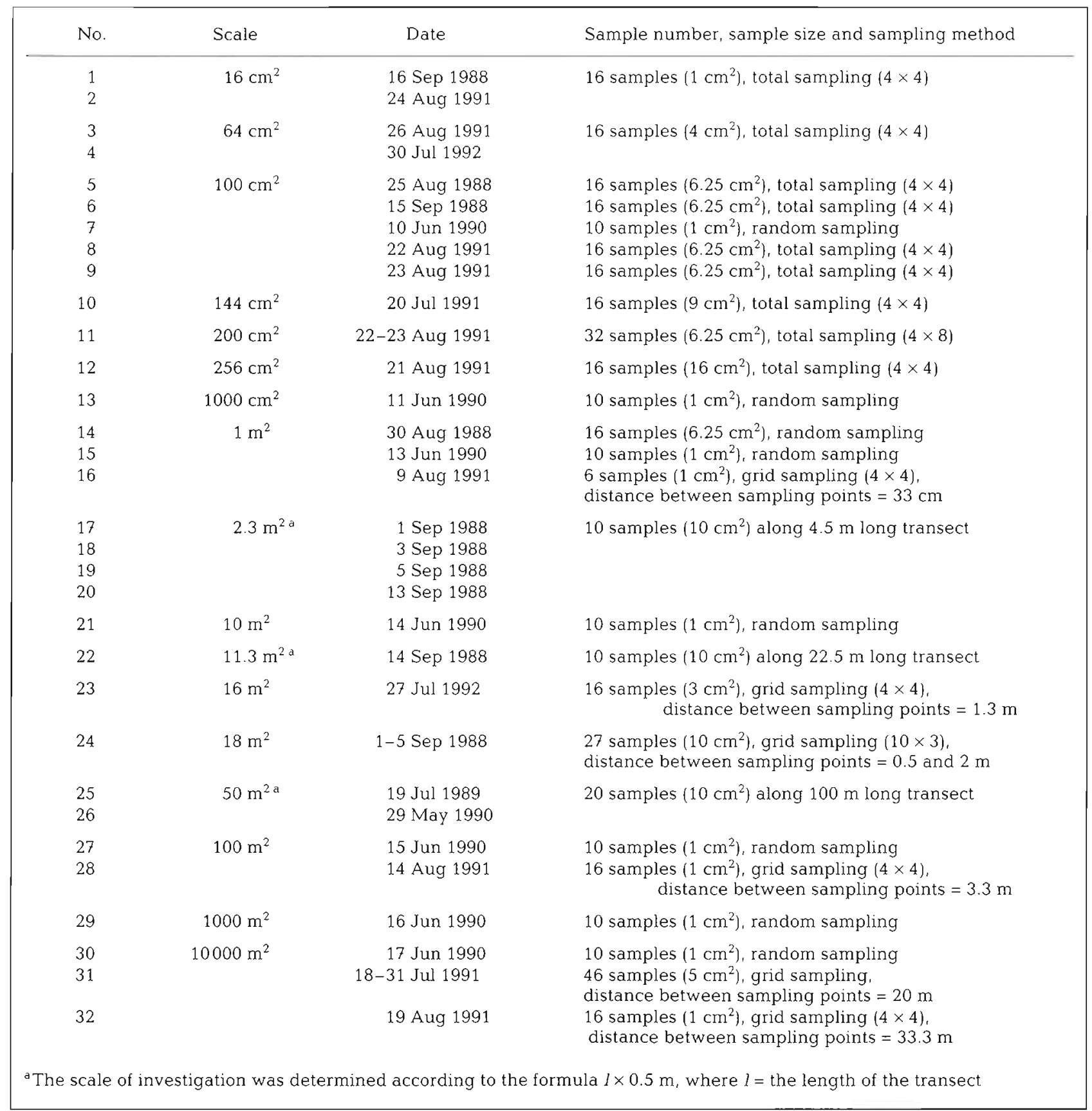

$\left(10 \mathrm{~cm}^{2}\right.$ to $\left.18 \mathrm{~m}^{2}\right)$ and macroscales (50 to $\left.10000 \mathrm{~m}^{2}\right)$ for the convenience of data presentation and analysis.

For microscale distribution we studied subjectively selected, relatively homogeneous areas, without stones, higher plants or macrobenthic deformation of sediment surface. The surveyed meso- and macroscale areas included different topographic features.

Organisms were extracted from sediments using Uhlig extraction cylinders (Uhlig 1964), substituting ice for filtered sea water. To the best of our knowledge, this method has not been used for extraction of interstitial microalgae from sediments. However, detailed microscopical examination of sand after full extraction showed that we were able to extract up to $95 \%$ of the large nonattached diatoms and dinoflagellates (Saburova \& Polikarpov 1989). The 11 most abundant species of large non-attached diatoms (60 to $100 \mu \mathrm{m}$ ) [the most abundant species in this ecological group were Gyrosigma recta 
(Donk.) Grun., Amphiprora paludosa W. Sm., Tropidoneis lepidoptera (Greg.) Cl., Pleurosigma nubecula W. Sm., Navicula humerosa Breb.] and 2 dominant species of dinoflagellates (Amphidinium britannicum C. E. Herdman, Gymnodinium sp.) as well as the main herbivorous ciliates were counted in vivo in Petri dishes using a dissection microscope.

The small attached diatoms 31 species; the most abundant were Amphora coffeaeformis (Ag.) $\mathrm{Cl}$., Amphora proteus Greg., Navicula salinarum Grun., Navicula pupula Ktz., Achnanthes sp., Nitzschia sp., Diploneis sp.] were fixed and stained with eosine yellowish alcohol solution to distinguish living cells from the empty valves. Diatoms were washed from sediments and centrifuged. The small cells were counted in a counting slide with a microscope.

Data analysis. The spatial distribution of organisms is described with different indexes (e.g. Cassie 1958, Farris \& Lindgren 1984, Pinckney \& Sandulli 1990). We selected the Cassie Index of aggregation (Cassie 1958) for assessment of spatial distribution characteristics, because it permits comparison of species and samples with different numbers as it depends less on the average density of organisms in a sample. The Cassie Index of aggregation is defined as:

$$
C=\frac{\sigma^{2}-n}{n^{2}}
$$

where $\sigma=$ standard deviation of abundance and $n=$ average abundance of organisms per sample. When $C$ $=0$ the distribution is random, at $C<0$ the distribution is even, and at $C>0$ it is aggregated.

To estimate the degree of aggregation of our community as a whole, we used the normalized Cassie Index ( $\dot{C}$ for all species on the $l$ th scale of space) according to the formula:

$$
\hat{C}=\frac{1}{i} \sum_{l=1}^{n} \frac{C_{i l}}{\frac{1}{l} \sum_{l=1}^{m} C_{l l}}
$$

where $C_{1}=$ the Cassie Index (see Eq. 1) of the $i$ th species out of $n$ such species in the 1 th spatial scale out of m such spatial scales.

Spatial overlapping of species was estimated using the Pianka Index (Pianka 1974) according to the formula:

$$
P_{l y}=\frac{\sum_{k=1}^{n} P_{i k} P_{j k}}{\sqrt{\sum_{k=1}^{n} P_{j k}{ }^{2} \sum_{k=1}^{n} P_{j k}{ }^{2}}}
$$

where $P_{\text {iulk }}=$ the portion of resource category $k$ (space) out of $n$ such categories utilized by the $i(j)$ th species.

The between-samples similarity $\left(P^{\prime}{ }_{1}\right)$ was estimated in the same way. In this case, $P_{1, j k}=$ the portion of species $k$ from $n$ of such species in the $i(j)$ th sample (Eq. 3 ).
Statistical and graphic analyses were carried out using SYSTAT v. 5.0 for DOS (SYSTAT, Inc.). To create the contour plots (Figs. 4 \& 5) we used shaded contour plotting, and to interpolate the data on organisms' spatial distribution in 16 contiguous samples we used distance weighted least squares (DWLS) smoothing (Wilkinson 1989).

\section{RESULTS AND DISCUSSION}

Analysis of spatial distribution of microphytobenthic organisms using the Cassie Index disclosed that, on the studied space scales, the distribution of most of the microalgae was aggregated.

Fig. 2 shows the dependency of the Cassie Index $(C)$ on the area of survey for several abundant species from the main systematic groups: Amphidinium britannicum, Gymnodinium sp. (Pyrrophyta), Amphiprora paludosa, and Pleurosigma nubecula (Bacillariophyta). It is obvious from the figure that all species, regardless of their taxonomic status, have a similar degree of aggregation in the interval of $10 \mathrm{~cm}^{2}$ to $10 \mathrm{~m}^{2}$ as well as a sharp increase in the aggregation index at larger size scales. These graphs show that the extent of aggregation of $A$. britannicum is greater than that of the other species on the macroscale.

Fig. 3 shows the dependence of the normalized index of aggregation $(\hat{C})$ on the spatial scale. The spatial structure of the surveyed community had at least 2 orders of aggregation. Aggregations of the first order reached 60 to $70 \mathrm{~cm}^{2}$ in size. Increasing the scale reveals aggregations of the second order with sizes of more than $1 \mathrm{~m}^{2}$

There are different ways to estimate the size of the patches, e.g. assessment of the degree of conformity between actual distribution and one of the theoretical models, each of which has its own quantitative characteristics of patchiness. However, in our opinion this approach is very artificial because actual distributions of species in natural, complexly organized communities do not conform well with 'ideal' models thus making conclusions based on this method debatable.

In addition to statistical assessment of patch sizes we used a direct technique, based on the analysis of schemes of horizontal distribution from total sampling data ( 16 contiguous (adjacent) subsamples from areas of $16,64,100,144$ and $\left.256 \mathrm{~cm}^{2}\right]$. Examples of such distributions are presented in Figs. 4 \& 5. Fig. 4 shows that the average size of $A$. britannicum aggregations on the microscale was about $70 \mathrm{~cm}^{2}$ Aggregations of other microalgae were of similar size (Fig. 5A, B, C, E). Our estimate of aggregation size is in good agreement with data on sizes of patches of the first order of aggregation (Fig. 3), given in the results of Pinckney \& Sandulli 
Fig. 2. Degree of aggregation of microalgal spatial distribution (the Cassie Index, $C_{i}$ see Eq. 1) according to investigation areas
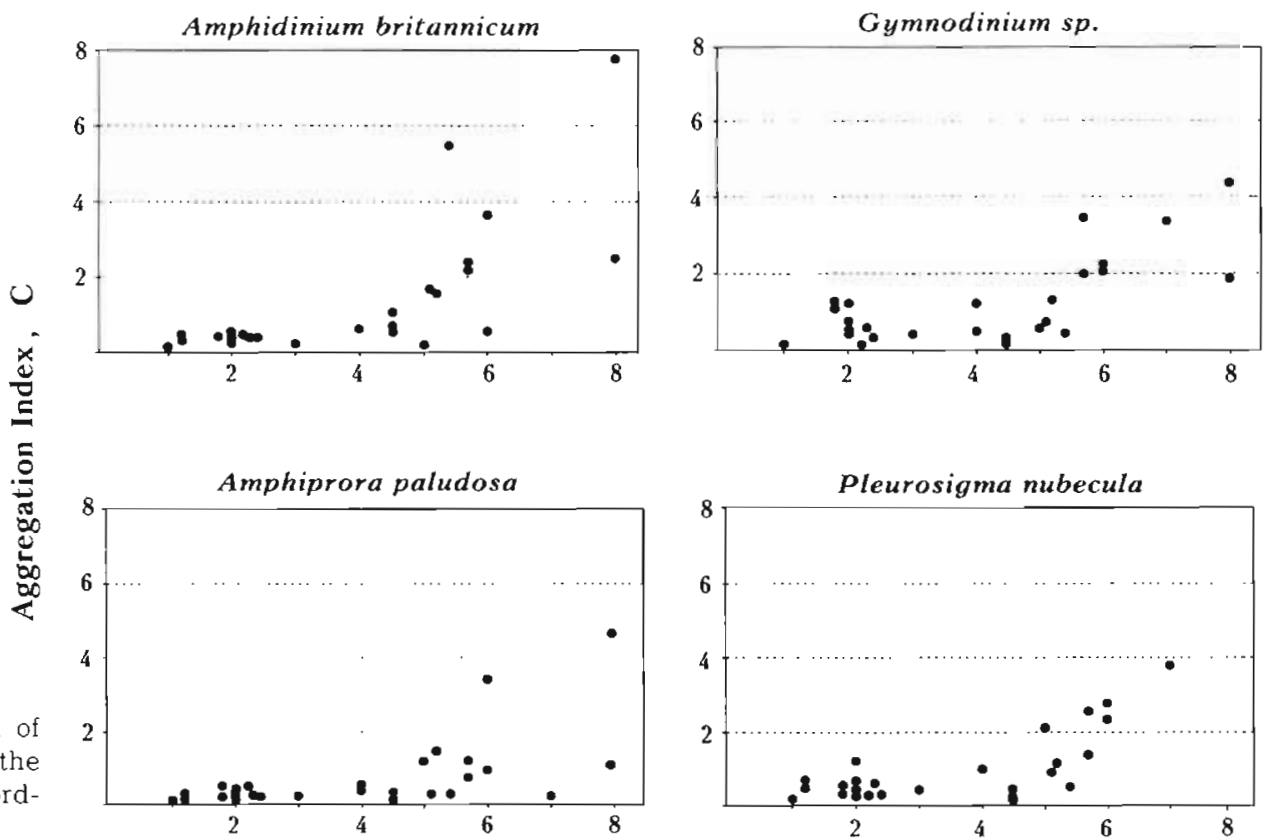

Log Investigated Spatial Scales, $\mathrm{cm}^{2}$

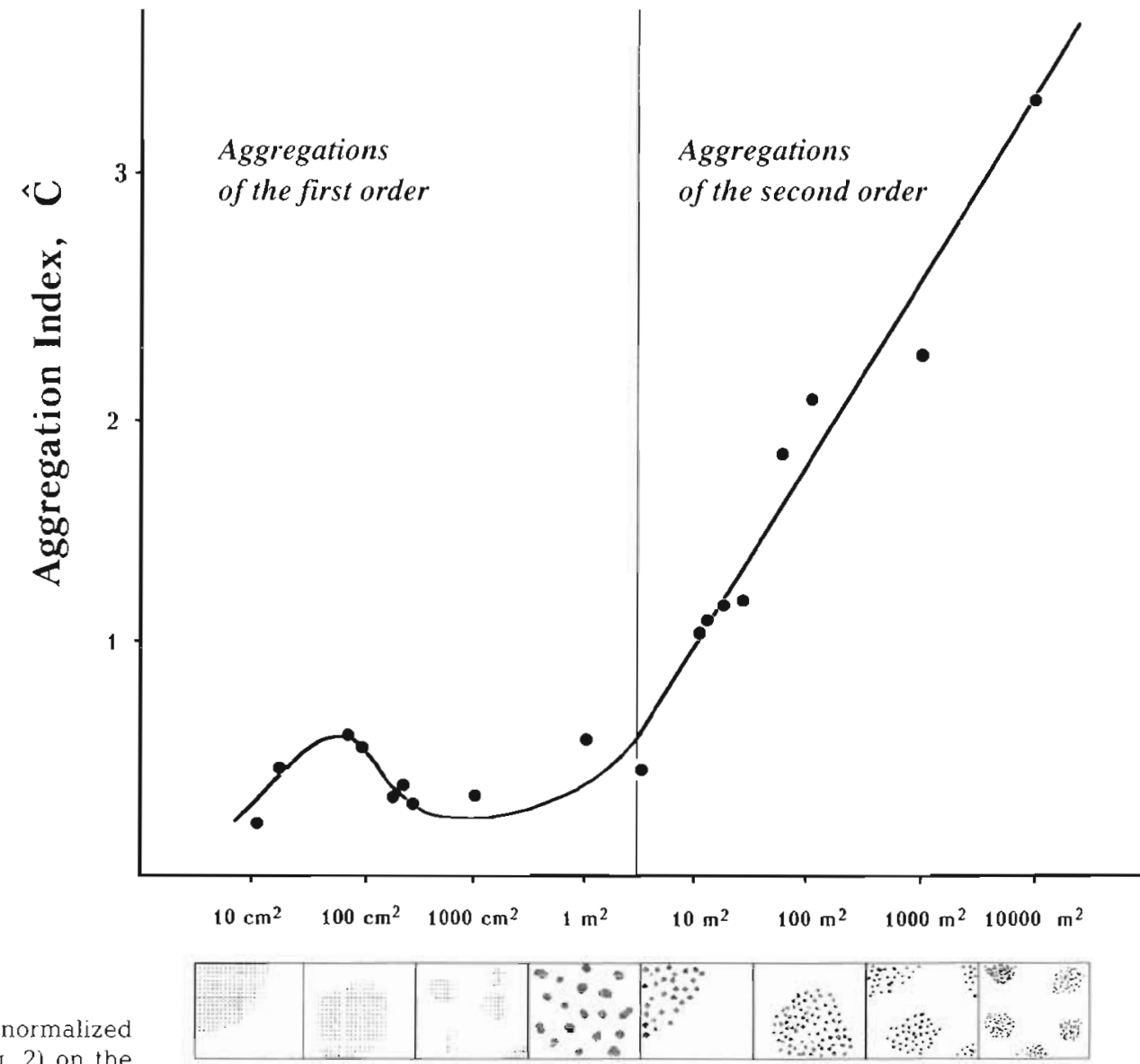

Fig. 3. Dependence of the normalized aggregation index $\left(\hat{C}_{i}\right.$ see Eq. 2$)$ on the
scale of investigation. Note that $x$ axis is scale of investigation. Note
logarithmic 
$4 \times 4 \mathrm{~cm}$

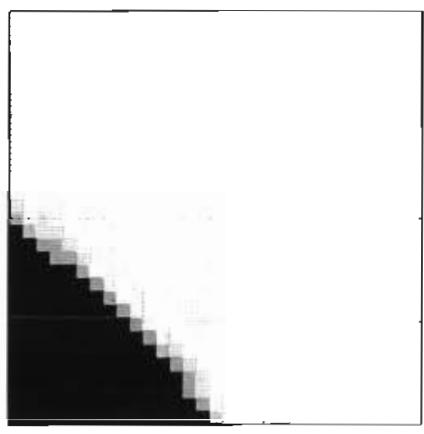

$1 \mathrm{~cm}$
$8 \times 8 \mathrm{~cm}$

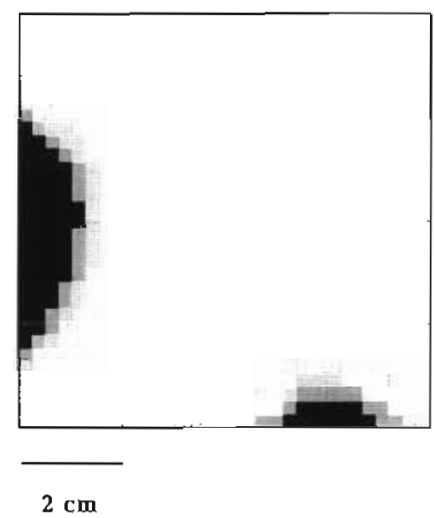

$16 \times 16 \mathrm{~cm}$

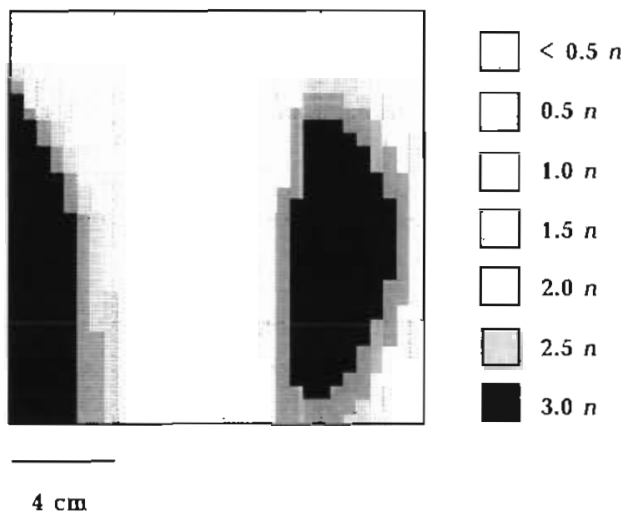

Fig. 4. Comparison of patch sizes of Amphidinium britannicum with different investigation areas on the microscale ( $n$ : average number of organisms per sample). Panels represent Nos. 2, 4 and 12 in Table 1

A

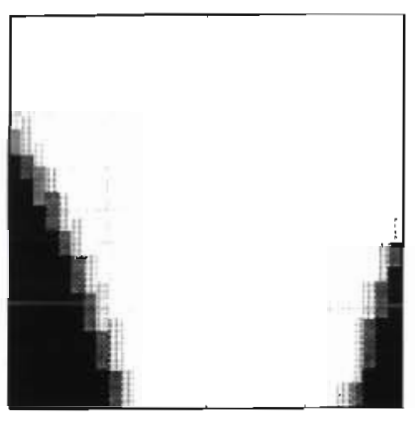

E

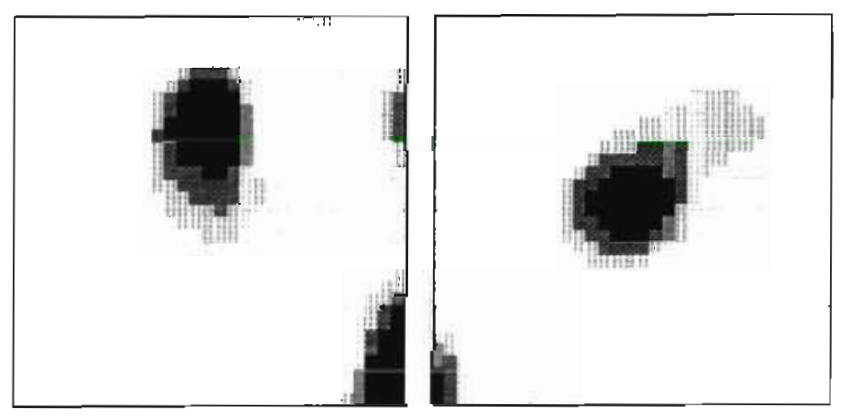

(1990), who reported patchy distribution of microalgae with mean patch diameters of about 6 to $8 \mathrm{~cm}(56$ to $100 \mathrm{~cm}^{2}$ ), and with data of Blanchard (1990) on patches of microphytobenthic organisms 4 to $113 \mathrm{~cm}^{2}$ in size. We observed similar patch sizes of interstitial ciliates, the dominant species of which were counted together with microalgae (Fig. 5D, F)

Absence of significant differences in the character of horizontal distribution, size of patches and spatial scales of aggregation of organisms belonging to differ-
C
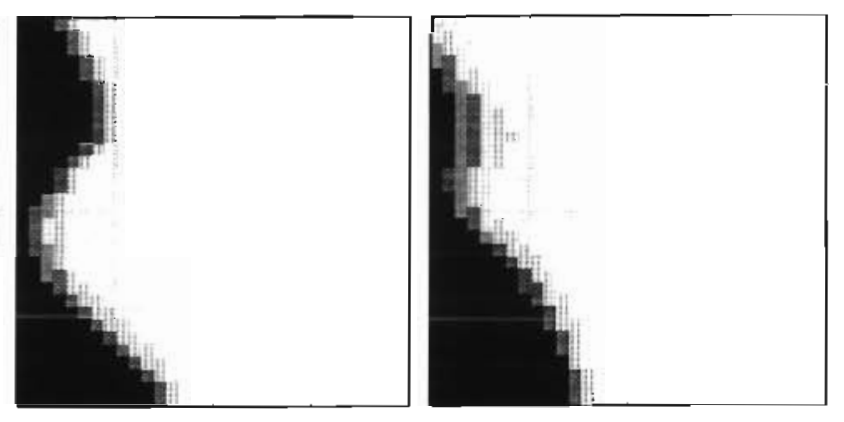

Fig. 5. Microscale spatial co-distribution of microbenthic organisms. (A) Amphidinium britannicum, (B) Amphiprora paludosa; Table 1, No.6. (C) Amphiprora paludosa, (D) abundance of herbivorous ciliates (genus Tracheloraphis); Table 1 , No. 8. (E) Pleurosigma nubecula, (F) abundance of herbivorous ciliates (genus Tracheloraphis); Table 1, No. 12. Different degrees of shading represent different organism densities (see symbol legend in Fig. 4)

ent systematic groups (but to similar size groups) may indicate that they have a similar sensitivity to the factors determining their distribution.

The similarity of patch sizes in different micro- and meiobenthic organisms has been described by Findlay (1981), Blanchard (1990), and Pinckney \& Sandulli (1990). In this context it is relevant to refer to Farris \& Lindgren (1984), who, based on a study of spatial codistribution of meiobenthic organisms, concluded that there was some optimal patch size inherent in all 
meiobenthic organisms from interstitial habitats. We conclude from our data that a similar phenomenon also characterizes the microbenthos.

The above results indicate the existence of an aggregated distribution pattern where physical and chemical features of areas are homogeneous. But what gives rise to the aggregated distribution of microalgae in an environment without distinct heterogeneity?

Many authors have noted that specific characteristics of microalgal distribution may depend on consumer organisms (Fenchel \& Kofoed 1976. Taasen \& Hoisater 1981, Davis \& Lee 1983, Montagna et al. 1983, Burkovsky 1984). For example, a positive correlation has been found between the distribution of herbivores and their potential prey (Montagna et al. 1983, Blanchard 1990. Pinckney \& Sandulli 1990). Pinckney \& Sandulli (1990) explained a high positive correlation between horizontal distribution of producers and consumers as being due to the absence of delay in the classic 'predator-prey' model. Such an absence may result from a high reproduction rate in microbenthic organisms. That is, the peaks in numbers of prey and predators would coincide in space and time. Thus, absence of a negative correlation between predators and their potential prey does not necessarily indicate the absence of grazing as a factor that could significantly influence structure, numbers and distribution of the microphytobenthos community.

However, based on data from experimental field and laboratory research, a number of investigators do not consider this factor to be significant. Bouvy (1988) reported that the nutritional requirement of meiofauna in a studied community was only $27 \%$ of the annual primary production of microphytobenthos, and a similar assessment of $10 \%$ was made by Admiraal et al. (1983).

The herbivorous ciliates, which were abundant in our community, always had different algae in their vacuoles (Burkovsky 1984). Taking into account the selective character of algal grazing by protozoa, consumption is potentially able to significantly influence the total numbers, species and size structure of the microphytobenthos. At the same time, in some cases a general tendency towards co-distribution of producers and consumers, observed by us as the occurrence of their aggregates in the same locus of a habitat (average Pianka Index of 0.77 ), could be traced. The maximum number of ciliates of the genus Tracheloraphis coincided in space with the patches of maximum abundance of microalgae (Fig. 5C, D). The most likely explanation for this is a high rate of microalgal reproduction. We observed that the production of microalgae at times far exceeded the total consumption, making the grazing effect negligible.

Competition of interstitial organisms for different resources may also potentially have a pronounced effect on spatial distribution of organisms (De Jong \& Admiraal 1984, Burkovsky 1987).

For example, competition for biogenic elements is a common phenomenon in phytoplankton blooms. However, the interstitial zone is characterized by a very high content of biogenic elements. The growth of benthic microalgae in water taken from the reduction zone of intertidal sediments is stronger than in traditional algal culture media and their components (Polikarpov \& Saburova 1990). As long as the flux of biogenic elements from interstitial water is high enough during a tidal cycle, it is obvious that competition for biogenic elements on intertidal mud-and sandflats cannot be a factor influencing spatial distribution of microalgae.

Compared with phytoplankton, benthic microalgae have much higher population densities (up to $10^{5}-10^{6}$ cells $\mathrm{cm}^{-2}$ ) (Taasen \& Hoisater 1981, Admiraal et al. 1982, McClatchie et al. 1982). The photic zone is 2.5 to $3.0 \mathrm{~mm}$ deep in the sand of our studied area (Burkovsky 1992), and most of the photosynthetic organisms are concentrated in this thin layer. Microphotographs of the surface and vertical sections of sediments from the intertidal mudflat, made using a lowtemperature scanning electron microscope technique (Paterson 1986, Paterson et al. 1986, Underwood \& Paterson 1993), have revealed a high density of individual algal cells in sediments. Diatoms are so abundant in the photic zone that they form a compact, often multilayered 'mat' on the surface of sediments and occur at all sediment depths over the entire photic zone. The high density may result in competition for light (the effect of self-shading) and in allopathic interactions between different species of algae due to high concentrations of excretions while they are alive.

When examining microalgae on spatial scales at which competitive or allopathic factors are expected to influence distribution, it appears that the spatial arrangement of different species is complementary (Fig. 5A, B). De Jong \& Admiraal (1984) obtained experimental evidence of species-specific allopathic interactions among benthic microalgae which confirms that the observed spatial divergence of species is influenced by metabolic factors. We observed a negatively dependent distribution only when definite threshold numbers of interacting organisms had been reached (in other words, the areas of maximum density of different species did not coincide in space). This also substantiates the occurrence of metabolic interactions or competition for space.

A similarity in spatial divergence of maximum density among different pairs of taxonomically close species of interstitial ciliates has been described earlier by Burkovsky (1992). These pairs of species are characterized by a high degree of overlapping of trophic niches and are influenced by 'diffusive' competition. This sim- 


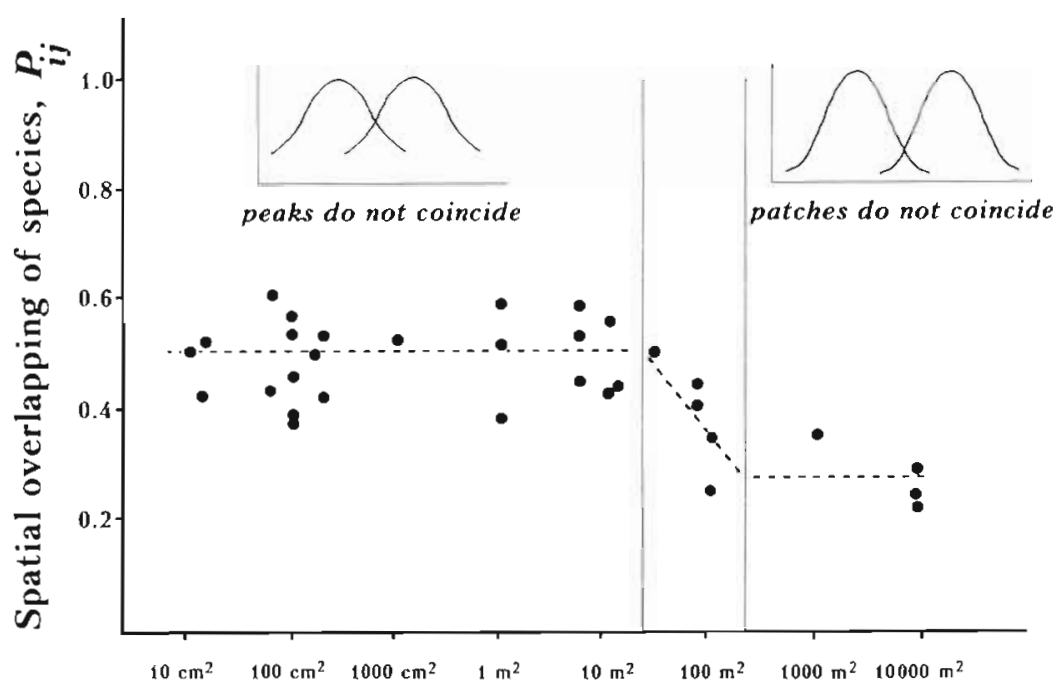

Log Investigated Spatial Scales, $\mathrm{cm}^{2}$

Fig. 6. Dependence between overlapping of spatial distribution ( $P_{i j}$; see Eq. 3) and scale of investigation in a microphytobenthic community
Paterson \& Underwood (1990) state that many physical and chemical factors influence populations of epipelic diatoms, but no universal factor is known that might control them.

The content of the fraction of sediment particles smaller than $0.1 \mathrm{~mm}$ and the density of adjacent particles are primary parameters on which other factors (water content, Eh, ion composition of pore water, light penetration, etc.) of the interstitial environment depend (Hargave 1972, Gurevich \& Khasankaev 1976, Burkovsky 1992). Another important characteristic of the intertidal zone - absolute altitude below low-water datum determines the range of variation of many abiotic factors such as temperature, salinity, water content and emersion period.

Proceeding from this, we attempted to assess the influence of these abiotic factors on algal spatial distribution.

ilarity also confirms our conclusion regarding the high probability of competitive or metabolic interactions in microalgae as the cause of their uneven microscale distribution.

Additional information about the nature of factors giving rise to microalgal aggregations is suggested by the dependence of the degree of similarity in species distributions (the Pianka Index, $P_{i j}$, Eq. 3 ) on the scale of the studied areas (Fig. 6). It is shown that the divergence of species in space increases with size of the sampling area. Species displayed coincident distributions (average $P_{i j}$ of $0.5)$ in areas of $10 \mathrm{~cm}^{2}$ to $10 \mathrm{~m}^{2}$, while beyond these limits differences in their distribution increased considerably (average $P_{i j}$ of 0.3 ). It is important to mention that the divergence in species' maximum density observed on the micro- and mesoscale occurred despite significant coincidence of species distributions within each sampling plot as a whole. However, overlapping between these aggregations decreased with increasing size of the surveyed areas The increasing heterogeneity of the environment with increasing area allows species to disperse in space according to a complex of environmental physical and chemical requirements.

Enlarging the investigation areas from $100 \mathrm{~m}^{2}$ to $10000 \mathrm{~m}^{2}$ permits the degree of influence of abiotic environmental factors upon spatial distribution to be assessed, because of the commensurability of the sampling areas with the scales of action of these factors. But which of the numerous physical and chemical factors that are responsible for formation of a specific habitat in the interstitial environment influence spatial distribution of microalgae most profoundly?
Fig. 7 demonstrates the dependence of abundance of the main groups of microphytobenthos (Amphidinium britannicum, Gymnodinium sp. and 11 species of nonattached diatoms) on topography of the sediment surface at the mesoscale. The samples were taken along the $22.5 \mathrm{~m}$ long transect, which crossed 5 sandy mounds such that odd-numbered sampling stations were on crests and even-numbered stations on the depressions between them. The figure shows that maximum numbers of all the microalgae coincided with the crests of the mounds. The main difference between sandy mounds and the depressions between them is the sediment texture. Sand in depressions is much siltier than on crests of mounds (aleuropelite content of $10 \%$ and $2.5 \%$, respectively). The emersion period of these areas does not differ significantly (by 20 to 40 min) and the influence of this factor is not strong. The differences between distribution of $A$. britannicum and diatoms (see Fig. 7) probably result from the specific morphology and behavior of these organisms. Large elliptical $A$. britannicum (60 to $80 \mu \mathrm{m}$ ) are highly mobile but are not able to penetrate into thin pores of silty sand. In contrast, the very flattened and elongate cells of diatoms, which slide on the substratum, are able to slide particles of sediment apart and penetrate into the sediment. Gymnodinium sp. are similarly mobile to $A$. britannicum but are smaller (about 30 to $40 \mu \mathrm{m}$ ). This probably permits this alga to exist at lower sediment depths together with diatoms. However, neither group reaches high numbers in this biotope.

Thus, the spatial distribution of microalgae on the mesoscale depends mostly on the granulometric com- 
position of sediments (and on factors influenced by particle size and density).

Fig. 8 shows the distribution of massoccurring species of microalgae along the $100 \mathrm{~m}$ transect made from the lower to upper intertidal zone. The figure shows that abundance maxima of different species of microalgae may be associated with different levels of the intertidal zone: Gymnodinium sp., Amphiprora paludosa and Nitzschia sp. with the lower and/or middle levels, and Amphora proteus, Achnanthessp. and Diploneis sp. with the upper level. Navicula pupula var. rostrata and Amphora coffeaeformis showed no preference for any particular level.

Thus, different macroalgal species inhabiting the intertidal zone form several complexes of species according to their levels in the intertidal sandflat. A similar distribution of diatom species on intertidal mudflats was noted by Paterson \& Underwood (1990). An important factor contributing to the formation of these groups is probably emersion period, which varies in the range of 0 to $4 \mathrm{~h} \mathrm{~d}^{-1}$ on the lower, 4 to $12 \mathrm{~h} \mathrm{~d}^{-1}$ on the middle and 12 to $20 \mathrm{~h} \mathrm{~d}^{-1}$ on the upper intertidal zone (see Fig 1).

This agrees with data on the degree of structural similarity between samples taken from areas of different size (Fig. 9). The high degree of similarity (average $P^{{ }^{\prime}}{ }_{i j}$ of 0.75 ) observed in the $10 \mathrm{~cm}^{2}$ to $1 \mathrm{~m}^{2}$ interval indicates that on this scale of space, we took samples within the limits of one structural association. A sharp decline in the value of $P^{\prime \prime}$ in the 1 to $100 \mathrm{~m}^{2}$ interval means that, by increasing the size of the investigation area, we left the boundaries of one association and expanded the station grid to a space containing many structural associations. In spite of the significant variation among the few data points in the third interval (1000 to 10000 $\mathrm{m}^{2}$ ), the tendency in it remains the same as in the first interval $\left(10 \mathrm{~cm}^{2}\right.$ to $\left.1 \mathrm{~m}^{2}\right)$, but to a lesser degree. This probably indicates that the number of different associations would not have increased if we had enlarged the scale of investigation.

Thus the spatial distribution of the microphytobenthic community investigated has an aggregated character. Spatial structures formed by aggregations of the first and second orders differ noticeably in

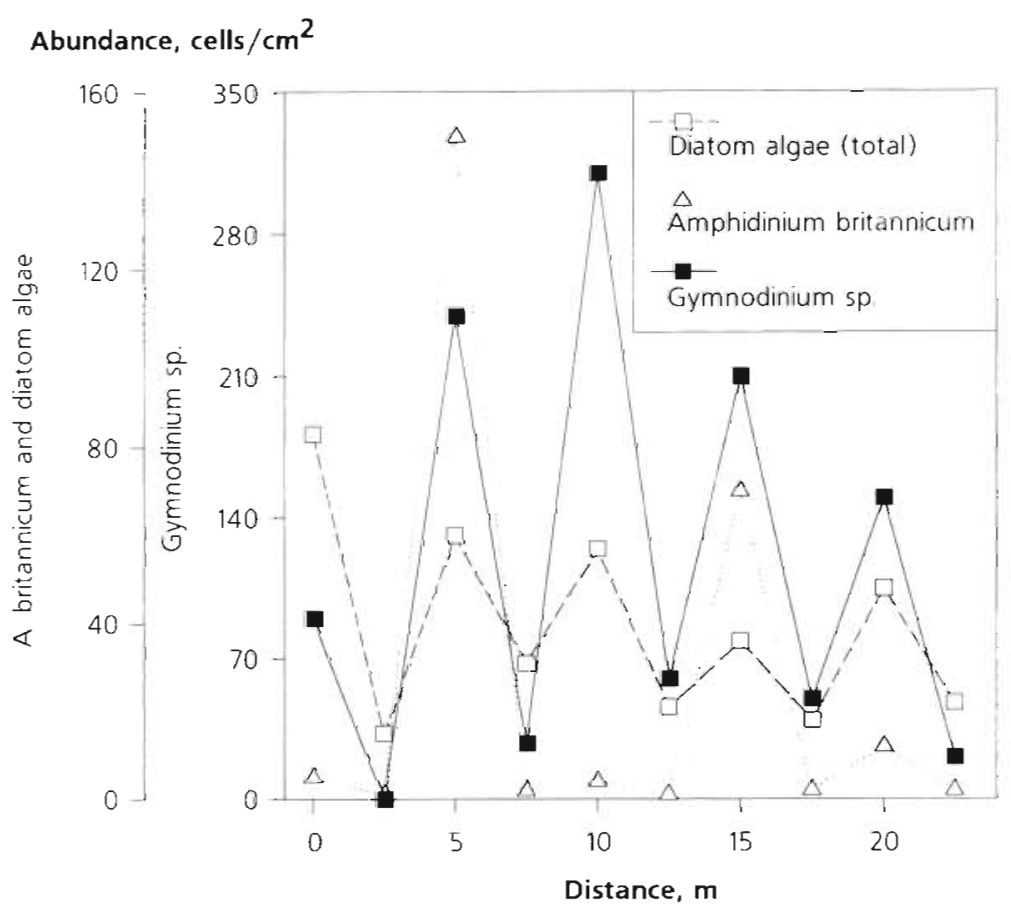

Fig. 7. Mesoscale distribution of microalgal groups along a transect (Table 1, No. 22)

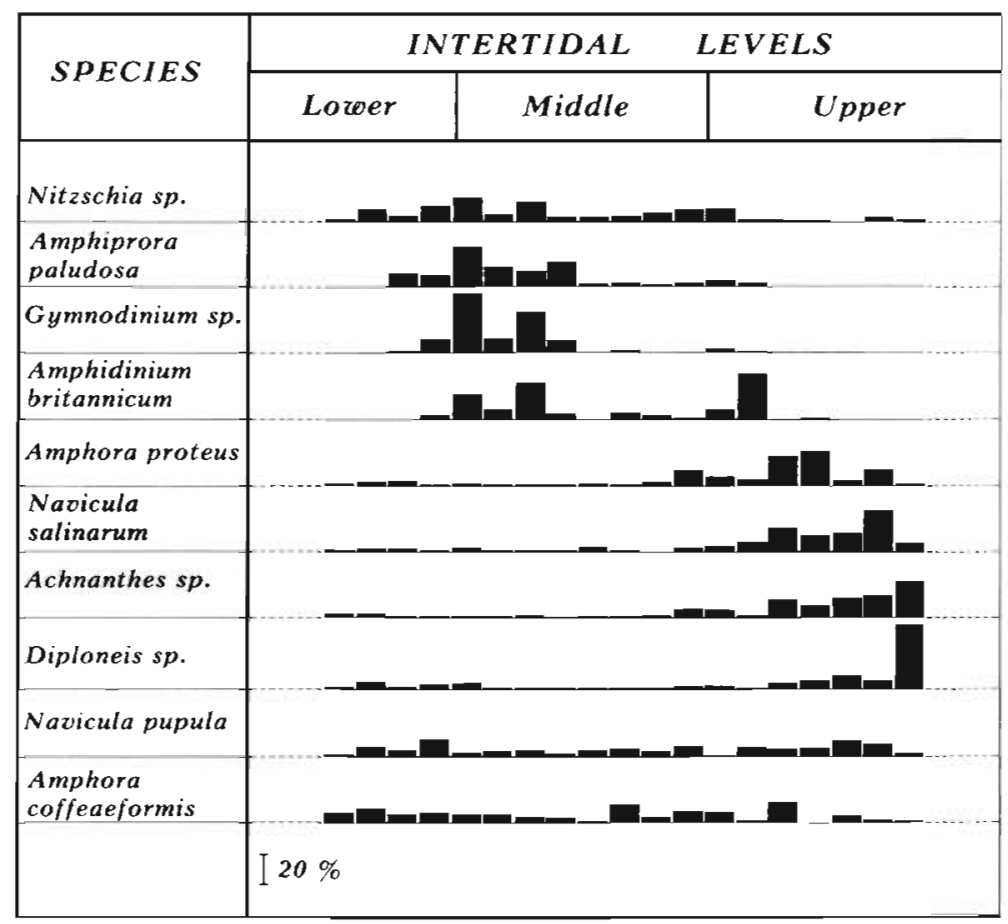

Fig. 8. Distribution pattern of several abundant microalgae along a transect (from lower to upper intertidal zone: Table 1, No. 25). Each bar represents abundance of the species relative to that species' total abundance within all samples along the transect 


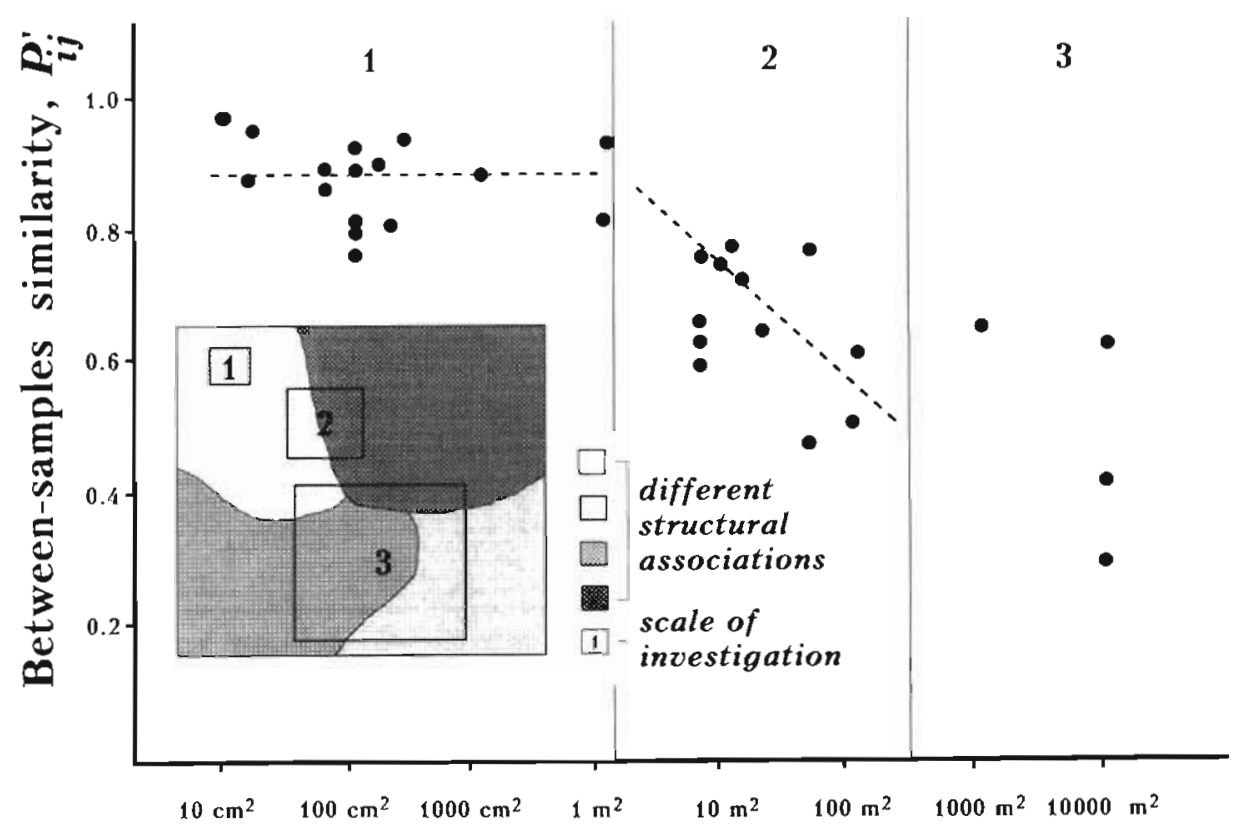

Fig. 9. Structural similarity of samples $\left(P_{1)}\right.$; see explanation below Eq. 3) taken from areas of different size

\section{Log Investigated Spatial Scales, $\mathrm{cm}^{2}$}

their degree of aggregation [average normalized Cassie Index $(\hat{C})$ of 0.5 and $>2$, respectively (Fig. 3)], value of overlapping of species distributions [average Pianka In$\operatorname{dex}\left(P_{j j}\right)$ of 0.5 and 0.3 (Fig. 6)] and degree of structural similarity [average between-species similarity $\left(P_{i j}\right)$ of 0.9 and 0.5 (Fig. 9)]. This indicates the existence of several structural associations in the studied intertidal sandflat which differ in their species composition and character of spatial distribution of organisms.

Depending on the investigation scale the spatial distribution of microalgae is caused by various factors:

(1) On the microscale, biotic interspecies interactions are most important; the extent of these interactions is commensurate with this spatial scale.

(2) On the mesoscale, distribution is mainly determined by the granulometric composition of sediments, and is strongly influenced by a complex of abiotic conditions in the sediments.

(3) On the macroscale, distribution depends on the emersion period during low tide.

Our conclusions agree with those of Paterson \& Underwood (1990) concerning the complex character of interactions between microalgae and environmental factors and shed new light on the mechanisms of spatial organization in microphytobenthic communities. At the same time, we believe it is important to draw attention to the high probability of competitive for metabolic) interrelations between microalgae (De Jong \& Admiraal 1984). These may also determine microspatial structure of the communities of unicellular organisms in soft bottoms.
Acknowledgements. The authors thank Drs A. Azovsky and V. Mokievsky for helpful remarks and comments on their manuscript as well as useful discussions. We are grateful to Dr Vincent Schultz for his kind help in correcting the English and valuable suggestions on an earlier draft of the manuscript. We also gratefully acknowledge 3 anonymous reviewers for their comments and suggestions on the manuscript.

\section{LITERATURE CITED}

Admiraal W, Bouwman L, Hoekstra L, Romeyn K (1983) Qualitative and quantitative interaction between microphytobenthos and herbivorous meiofauna on a brackish intertidal mudflat. Int Rev ges Hydrobiol 68:175-191

Admiraal W. Peletier H, Zomer H (1982) Observations and experiments on the population dynamics of epipelic diatoms from an estuarine mudflat. Estuar coast Shelf Sci 14:471-487

Blanchard GF (1990) Overlapping microscale dispersion patterns of meiofauna and microphytobenthos. Mar Ecol Prog Ser 68:101-111

Bouvy M (1988) Contrubution of the bacterial and microphytobenthic microflora in the energetic demand of the meiobenthos in an intertidal muddy sediment (Kerguelen Archipelago). PSZN I: Mar Ecol 9:109-122

Burkovsky IV (1984) Ecology of free-living ciliates. Moscow State University, Moscow (in Russian)

Burkovsky IV (1987) Dividing of ecological resources and interrelations of species in the marine psammophilic ciliates community. Zool Zh 66:645-654 (in Russian)

Burkovsky IV (1992) Structure-functional organization and stability of marine benthic communities. Moscow State University, Moscow (in Russian)

Cassie RM (1958) Apparatus for investigating spatial distribution of plankton. NZ J Sci 1:436-448

Colijn F, Dijkema KS (1981) Species composition of benthıc 
diatoms and distribution of chlorophyll $a$ on an intertidal flat in the Dutch Wadden Sea. Mar Ecol Prog Ser 4:9-21

Davis MW, Lee HH (1983) Recolonization of sediment-associated microalgae and effect of estuarine infauna on microalgal production. Mar Ecol Prog Ser 11:227-232

De Jong L, Admiraal W (1984) Competition between three estuarine benthic diatoms species in mixed cultures. Mar Ecol Prog Ser 18:269-275

Delgado M (1989) A.bundance and distribution of microphytobenthos in the bays of Ebro Delta (Spain). Estuar coast Shelf Sci 29:183-194

Farrss RA, Lindgren EW (1984) A posteriori investigation of spatial arrangements in Gnathostomulida and Copepoda. Int Rev ges Hydrobiol 69:443-450

Faure-Fremiet E (1951) The tidal rhythm of diatom Hantzschia amphioxys. Biol Bull 100:173-177

Fenchel T (1969) The ecology of marine microbenthos. Ophelia $6: 1-182$

Fenchel T, Kofoed LH (1976) Evidence for exploitative interspecific competition in mud snails (Hydrobiidae). Oikos $27: 367-376$

Findlay SEG (1981) Small-scale spatial distribution of meiofauna on a mud-and sandflat. Estuar coast Shelf Sci 12 : $471-484$

Gurevich VI, Khasankaev VB (1976) Lithological parameters of intertidal sandflat biogeocenoses on Dalniy Beach. Ecological investigation of intertidal sandflat. Cola branch, Academy of Sciences of the USSR, Apatıty, p 3-25 (in Russian)

Hargave BT (1972) Aerobic decomposition of sediment and detritus as a function of particle surface area and organic content. Limnol Oceanogr 17:583-596

Hirano R (1967) Mechanisms of development of red tide in estuarine waters. Inform Bull Planktol Jap Commemoration Number of Dr. Y. Matue: 25-29

Joseph MM, Joseph S (1977) Interstitial euglenoids and diatoms causing colouration of Mangalore Beach sand during low tides. Indian J mar Sci 6:179-180

McClatchie S, Juniper SK, Knox GA (1982) Structure of a mudflat diatom community in the Avon-Heathcote estuary, New Zealand. NZ J mar Freshwat Res 16:299-309

Montagna PA, Coull BC, Herring TL, Dudley BW (1983) The relationship between abundances of meiofauna and their suspected microbial food (diatoms and bacteria). Estuar coast Shelf Sci 17:381-394

This article was submitted to the editor
Paterson DM (1986) The migratory behavior of diatom assemblages in a laboratory tidal micro-ecosystem examined by low temperature scanning electron microscopy. Diatom Res 1(2): 227-239

Paterson DM. Crawford RM, Little C (1986) The structure of benthic diatom assemblages: a preliminary account of the use and evaluation of low-temperature scanning electron microscopy. J exp mar Biol Ecol 96:279-289

Paterson DM, Underwood GCJ (1990) The mudflat ecosystem and epipelic diatoms. Proc Bristol Naturalists' Soc 50: $74-82$

Pianka EP (1974) Niche overlap and diffuse competition. Proc Natl Acad Sci USA 71:2141-2145

Pinckney J, Sandulli R (1990) Spatial autocorrelation analysis of meiofaunal and microalgal populations on an intertidal sandflat: scale linkage between consumers and resources. Estuar coast Shelf Sci 30:341-353

Plante R, Plante-Cuny MR, Reys JP (1986) Photosynthetic pigments of sandy sediments on the North Mediterranean coast: their spatial distribution and its effect on sampling strategies. Mar Ecol Prog Ser 34:133-141

Polikarpov IG, Saburova MA (1990) Growth of benthic microalgae on medium from reduction zone of littoral sand sediments. Proc Acad Sci USSR 310:253-256 (in Russian).

Saburova MA, Polikarpov IG (1989) Comparative analysis of some methods of quantitative count of benthic diatom algae. In: 20th Conference of young scientists of the Biological Faculty. Part 2. Moscow State University, Moscow, p $109-113$ (in Russian)

Skjoldal HR (1982) Vertical and small-scale horizontal distribution of chlorophyll a and ATP in subtropical beach sand. Sarsia 67:79-83

Taasen JP, Hoisater G (1981) The shallow-water soft-bottom benthos in Lindaspollene, Western Norway. 4. Benthic marine diatoms, seasonal density fluctuations. Sarsia 66: $292-316$.

Uhlig G (1954) Eine einfache Methode zur Extraktion der vagilen, mesopsammolen Mikrofauna. Helgolandänder wiss Meeresunters 11:178-185

Underwood GCJ, Paterson DM (1993) Recovery of intertidal benthic diatoms after biocide treatment and associated sediment dynamics. J mar biol Ass UK 73:25-45

Wilkinson L (1989) SYSTAT: the system for statistics. SYSTAT Inc, Evanston, IL

Manuscript first received: May 24, 1994

Revised version accepted: April 19, 1995 